\title{
Forward Position Analysis of the SP-PS-RS Architectures
}

\author{
R. Di Gregorio
}

\begin{abstract}
A wide family of parallel manipulators (PMs) is the one that groups all the PMs with three legs where the legs become kinematic chains constituted of a passive spherical pair (S) in series with either a passive prismatic pair (P) or a passive revolute pair $(R)$ when the actuators are locked. The topologies of the structures generated by these manipulators, when the actuators are locked, are ten. One out of these topologies is the SP-PS-RS topology. This paper presents an algorithm that determines all the assembly modes of the structures with topology SP-PS-RS in analytical form. The presented algorithm can be applied without changes to solve, in analytical form, the forward position analysis of any parallel manipulator (SP-PS-RS architecture) which generates a SP-PS-RS structure when the actuators are locked. In particular, the closure equations of a generic SP-PS-RS structure are written. The eliminant of this system of equations is determined and the solution procedure is presented. Finally, the proposed procedure is applied to a real case. This work demonstrates that the solutions of the forward position analysis of any parallel manipulator which generates a SP-PS-RS structure when the actuators are locked are at most twelve.
\end{abstract}

Index Terms - kinematics, position analysis, parallel mechanisms, parallel structure.

\section{INTRODUCTION}

$\mathrm{P}$ ARALLEL MANIPULATORs (PMs) are mechanisms with only closed kinematic chains (loops). As a consequence, in PMs, the end effector is connected to the frame through a number of kinematic chains (legs) and the number of kinematic pairs is much greater than the number of degrees of freedom (dof) of the manipulator which implies the presence of many non-actuated joints (passive joints). The contemporary action of the legs on the end effector allows high stiffness and positioning precision to be reached by PMs in nearly all their workspace. These features made them suitable for various applications: testing machines [1], simulators [2], precision cranes [3-7], etc.

Parallel manipulators with three legs constitute a wide family of manipulators. For instance, the majority of three-dof PMs proposed in the literature belong to this family [8-24].

This work was supported by MIUR (Italian Ministry of University and Research) funds.

R. Di Gregorio is with the Department of Engineering, Ferrara University, Via Saragat 1, 44100 FERRARA, ITALY (phone: +39-0532-974828; fax: +39-0532-974870; e-mail: rdigregorio@ing.unife.it).
When the active joints are locked, three-legged PMs yield closed structures consisting of two rigid bodies (base and platform) connected through three legs with only passive joints. The end effector and the frame become the platform and the base of the structure respectively. If the three-legged PM is not overconstrained [25], the closed structure is an isostatic structure that may have either three legs with connectivity four or one leg with connectivity three, another leg with connectivity four and the remaining leg with connectivity five (leg's connectivity is the sum of the dof of all the joints belonging to the leg reduced to a serial kinematic chain).

An one-to-one correspondence exists between the assembly modes without link permutation of a closed structure and the solutions of the forward position analysis (FPA) of the PM generating that structure, since the FPA solutions are the endeffector poses (positions and orientations) the end effector can assume when the active joints are locked. One effective way to find algorithms that solve the FPA of wide sets of PMs is the search of algorithms that determine the assembly modes of closed structures with a given topology, because the PMs differing only for the type and/or the location of the active joints generate closed structures with the same topology. The availability of algorithms that solve the FPA allows efficient control technique to be implemented.

In general, the analytic form solution of the FPA of a PM is a difficult problem that involves the solution of non-linear equation systems. In the literature, much attention has been paid to the FPA of the Stewart platforms (see [26] for references) and their general case has been just recently solved [27-30].

Stewart platforms are six-dof PMs that, when the active joints are locked, become closed structures with six legs of type SS (S stands for spherical pair) (Fig. 1). Different types of such closed structures have coincident spherical-pairs' centers either in the base or in the platform according to the type of Stewart platform that generates them. Combining SS legs, either legs of type S (Fig. 2) or legs of type RS (Fig. 3) (R stands for revolute pairs) may be modeled. Therefore, algorithms that solve the FPA of Stewart platforms are applicable to the solution of the FPA of PMs, that, when the active joints are locked, generate closed structures with legs of type S or RS. Three-legged closed structures with RS (or SR) legs are the 3RS and the SR-2RS that have been solved in [31] and [32] respectively. 


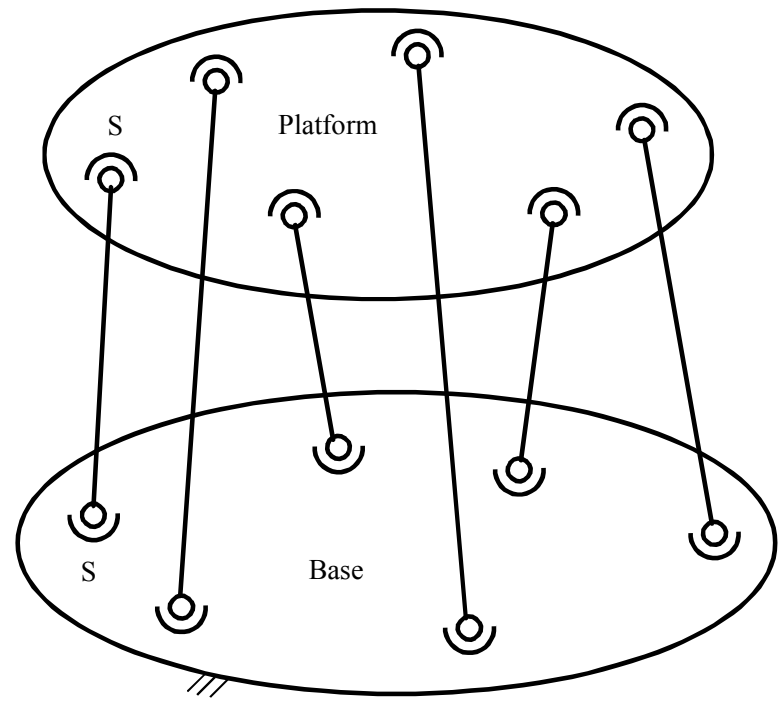

Fig. 1: Closed structure with 6SS topology (S stands for spherical pair)

Unfortunately, when a passive prismatic pair is present in one or more-than-one legs of a PM, the algorithms that solve the FPA of the Stewart platforms are no longer applicable.

This work closes a research activity devoted to develop efficient algorithms for the analytical solution of the FPA of three-legged PMs which, when the active joints are locked, become closed structures with three connectivity-four legs constituted by a spherical pair, S, in series with either a prismatic pair, $\mathrm{P}$, or a revolute pair, $\mathrm{R}$ (i.e. legs of the following types: PS, RS, SP and SR). The topologies of the structures generated by these manipulators can be obtained by listing all the possible combinations of three legs with one out of the four topologies PS, RS, SR and SP and deleting from the list all the structures that become an already listed structure when the leg order is permuted or platform and base are interchanged. So doing, the following ten structures with different topology are determined: 3PS, 3RS, PS-2RS, RS2PS, SP-2PS, SR-2RS, SR-2PS, SP-2RS, SR-PS-RS and SPPS-RS.

Algorithms which analytically determine the assembly modes of the first nine structures have been already presented in [33] (3PS), [31] (3RS), [34] (PS-2RS and RS-2PS), [35] (SP-2PS), [32] (SR-2RS), [36] (SR-2PS), [37] (SP-2RS) and [38] (SR-PS-RS).

Only the SP-PS-RS structure (Fig. 4) has not been studied yet.

This paper presents an algorithm that determines in analytical form all the assembly modes of the structures with topology SP-PS-RS. The presented algorithm can be applied without changes for solving in analytical form the FPA of all the PMs that become SP-PS-RS structures when the active joints are locked.

In particular, the system of the closure equations for a generic SP-PS-RS structure will be written. The eliminant of such a system will be determined and the solution procedure will be presented. Finally, the proposed procedure will be

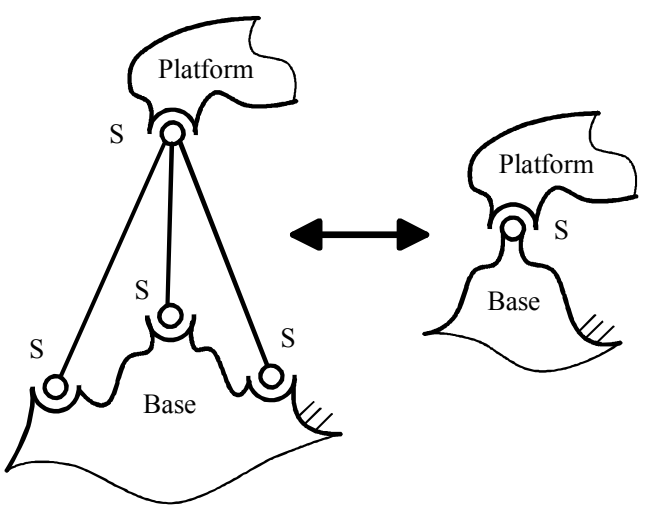

Fig. 2: Three legs of SS type combined to give one leg of S type (i.e. a spherical pair joining platform and base)

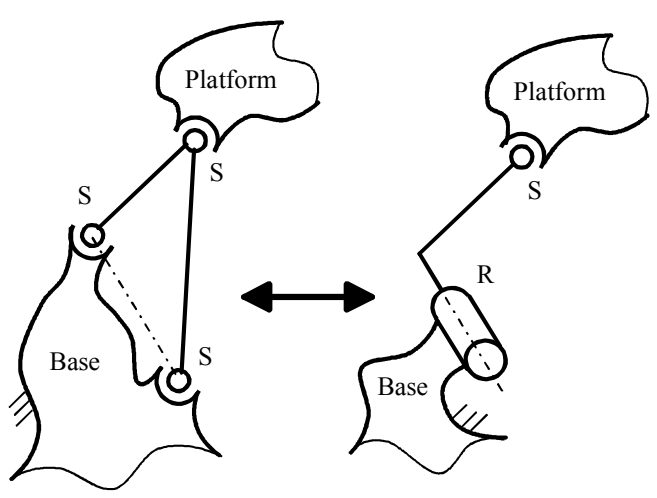

Fig. 3: Two legs of SS type combined to give one leg of RS type

applied to a real case.

This work demonstrates that the solution of the FPA of any PM that become a SP-PS-RS structure when the active joints are locked are at most twelve.

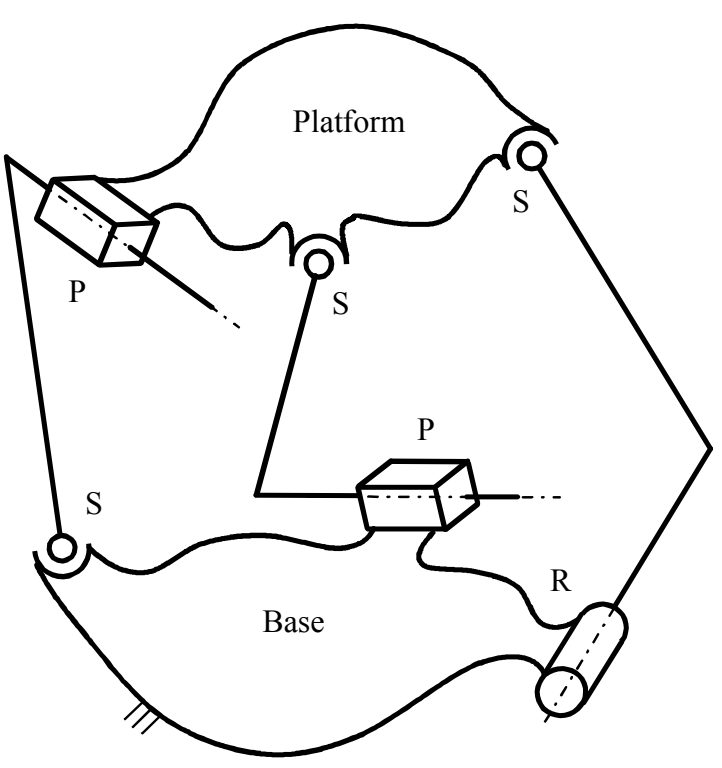

Fig. 4: Structure with SP-PS-RS topology 


\section{NotATIONS AND Closure EQUATIONS}

Figure 5 shows the notations that will be used. With reference to Fig. 5, A is the center of the spherical pair of the base. $\mathbf{m}$ is a unit vector parallel to the sliding direction of the prismatic pair of the platform. $\mathrm{A}_{0}$ is a given point of the platform lying on the line through $\mathrm{A}$ and parallel to $\mathbf{m}$. $\mathrm{a}$ is the signed distance from $\mathrm{A}_{0}$ to $\mathrm{A}$, it is positive when the vector $\left(\mathbf{A}-\mathbf{A}_{0}\right)$ has the same direction as $\mathbf{m}$ and it is the joint variable of the prismatic pair of the platform. $\mathrm{B}$ is the center of spherical pair that joins the RS leg to the platform. $B_{0}$ is the foot of the perpendicular through $\mathrm{B}$ to the revolute pair axis, whose unit vector is $\mathbf{u}$. $\mathbf{u}$ and $\mathbf{v}$ are two mutually orthogonal unit vectors embedded in the base. $b$ is the length of the segment $B_{0} B . \varphi$ is the joint variable of the revolute pair $[\varphi$ is equal to zero when the vector $\left(\mathbf{B}-\mathbf{B}_{0}\right)$ is parallel to $\mathbf{v}$ and has the same direction as $\mathbf{v}$; it measures the angle, counterclockwise with respect to $\mathbf{u}$, from $\mathbf{v}$ to $\left.\left(\mathbf{B}-\mathbf{B}_{0}\right)\right]$. $\mathrm{C}$ is the center of the spherical pair that joins the PS leg to the platform. $\mathbf{s}$ is the unit vector of the sliding direction of the prismatic pair of the base. $\mathrm{C}_{0}$ is a given point of the base lying on the line through $\mathrm{C}$ and parallel to $\mathbf{s}$. $\mathrm{q}$ is the signed distance from $\mathrm{C}_{0}$ to $\mathrm{C}$, it is positive when the vector $\left(\mathbf{C}-\mathbf{C}_{0}\right)$ has the same direction as $\mathbf{s}$ and it is the joint variable of the prismatic pair of the base. $S_{b}$ and $S_{p}$ are two Cartesian reference systems embedded in the base and in the platform respectively. Hereafter, the vectors with a superscript $b(p)$ on the left are projected on $\mathrm{S}_{\mathrm{b}}\left(\mathrm{S}_{\mathrm{p}}\right)$ and, if they are position vectors, they are defined and projected on $S_{b}\left(S_{p}\right)$. Finally, $d$ will be the length of the segment BC.

With these notations, the closure equations of a SP-PS-RS structure can be written in the following way:

$\left({ }^{\mathrm{b}} \mathbf{B}-{ }^{\mathrm{b}} \mathbf{C}\right) \cdot\left({ }^{\mathrm{b}} \mathbf{B}-{ }^{\mathrm{b}} \mathbf{C}\right)=\mathrm{d}^{2}$

$\left({ }^{\mathrm{b}} \mathbf{B}-{ }^{\mathrm{b}} \mathbf{A}\right) \cdot\left({ }^{\mathrm{b}} \mathbf{B}-{ }^{\mathrm{b}} \mathbf{A}\right)=\left({ }^{\mathrm{p}} \mathbf{B}-{ }^{\mathrm{p}} \mathbf{A}\right) \cdot\left({ }^{\mathrm{p}} \mathbf{B}-{ }^{\mathrm{p}} \mathbf{A}\right)$

$\left({ }^{\mathrm{b}} \mathbf{C}-{ }^{\mathrm{b}} \mathbf{A}\right) \cdot\left({ }^{\mathrm{b}} \mathbf{C}-{ }^{\mathrm{b}} \mathbf{A}\right)=\left({ }^{\mathrm{p}} \mathbf{C}-{ }^{\mathrm{p}} \mathbf{A}\right) \cdot\left({ }^{\mathrm{p}} \mathbf{C}-{ }^{\mathrm{p}} \mathbf{A}\right)$

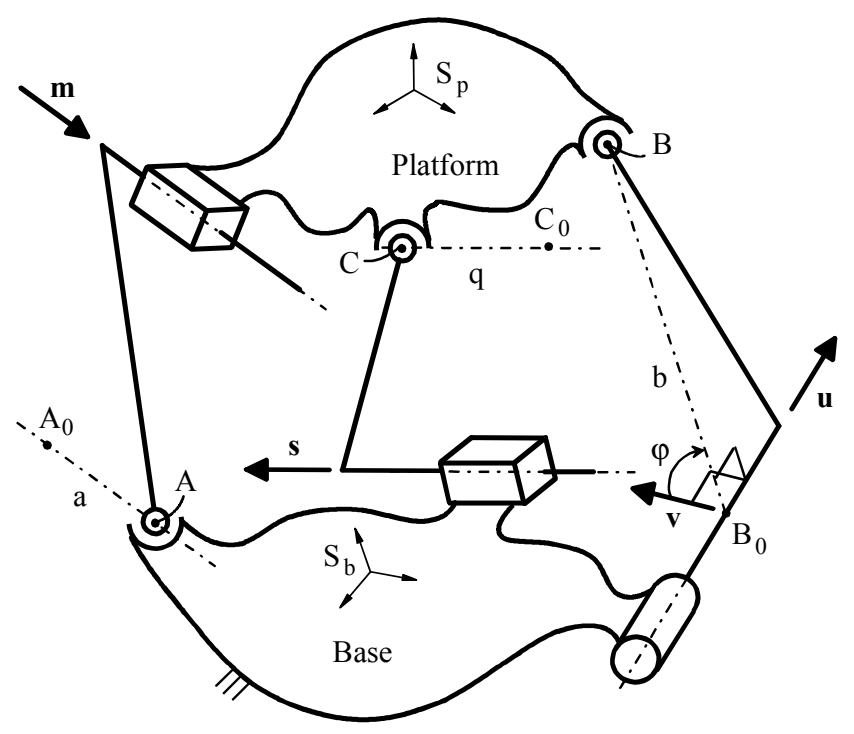

Figure 5: Notations where

$\begin{aligned}{ }^{\mathrm{p}} \mathbf{A} & ={ }^{\mathrm{p}} \mathbf{A}_{0}+\mathrm{a}^{\mathrm{p}} \mathbf{m} \\ { }^{\mathrm{b}} \mathbf{B} & ={ }^{\mathrm{b}} \mathbf{B}_{0}+\mathrm{b}\left({ }^{\mathrm{b}} \mathbf{v} \cos \varphi+{ }^{\mathrm{b}} \mathbf{u} \times{ }^{\mathrm{b}} \mathbf{v} \sin \varphi\right) \\ { }^{\mathrm{b}} \mathbf{C} & ={ }^{\mathrm{b}} \mathbf{C}_{0}+\mathrm{q}^{\mathrm{b}} \mathbf{s}\end{aligned}$

The introduction of (2) into (1) transforms system (1) as follows

$\mathrm{e}_{1} \cos \varphi+\mathrm{f}_{1} \sin \varphi=\mathrm{g}_{1}$

$\mathrm{e}_{2} \cos \varphi+\mathrm{f}_{2} \sin \varphi=\mathrm{j}_{2}$

$\mathrm{a}^{2}=\mathrm{g}_{2}-\mathrm{j}_{1} \mathrm{a}$

where

$\mathrm{e}_{1}=\mathrm{e}_{01}+\mathrm{qe}_{11}$

$\mathrm{e}_{01}=2 \mathrm{~b}\left({ }^{\mathrm{b}} \mathbf{B}_{0}-{ }^{\mathrm{b}} \mathbf{C}_{0}\right) \cdot{ }^{\mathrm{b}} \mathbf{v}$

$\mathrm{e}_{11}=-2 \mathrm{~b}{ }^{\mathrm{b}} \mathbf{v} \cdot{ }^{\mathrm{b}} \mathbf{s}$

$\mathrm{f}_{1}=\mathrm{f}_{01}+\mathrm{qf}_{11}$

$\mathrm{f}_{01}=2 \mathrm{~b}\left({ }^{\mathrm{b}} \mathbf{B}_{0}-{ }^{\mathrm{b}} \mathbf{C}_{0}\right) \cdot\left({ }^{\mathrm{b}} \mathbf{u} \times{ }^{\mathrm{b}} \mathbf{v}\right)$

$\mathrm{f}_{11}=-2 \mathrm{~b}\left({ }^{\mathrm{b}} \mathbf{u} \times{ }^{\mathrm{b}} \mathbf{v}\right) \cdot{ }^{\mathrm{b}} \mathbf{s}$

$\mathrm{g}_{1}=-\mathrm{q}^{2}+\mathrm{g}_{11} \mathrm{q}+\mathrm{g}_{01}$

$\mathrm{g}_{01}=\mathrm{d}^{2}-\mathrm{b}^{2}-\left({ }^{\mathrm{b}} \mathbf{B}_{0}-{ }^{\mathrm{b}} \mathbf{C}_{0}\right) \cdot\left({ }^{\mathrm{b}} \mathbf{B}_{0}-{ }^{\mathrm{b}} \mathbf{C}_{0}\right)$

$\mathrm{g}_{11}=2\left({ }^{\mathrm{b}} \mathbf{B}_{0}-{ }^{\mathrm{b}} \mathbf{C}_{0}\right) \cdot{ }^{\mathrm{b}} \mathbf{s}$

$\mathrm{e}_{2}=2 \mathrm{~b}\left({ }^{\mathrm{b}} \mathbf{B}_{0}-{ }^{\mathrm{b}} \mathbf{A}\right) \cdot{ }^{\mathrm{b}} \mathbf{v}$

$\mathrm{f}_{2}=2 \mathrm{~b}\left({ }^{\mathrm{b}} \mathbf{B}_{0}-{ }^{\mathrm{b}} \mathbf{A}\right) \cdot\left({ }^{\mathrm{b}} \mathbf{u} \times{ }^{\mathrm{b}} \mathbf{v}\right)$

$\mathrm{j}_{2}=\mathrm{a}^{2}+\mathrm{j}_{12} \mathrm{a}+\mathrm{j}_{02}$

$\mathrm{j}_{02}=\left({ }^{\mathrm{p}} \mathbf{B}-{ }^{\mathrm{p}} \mathbf{A}_{0}\right) \cdot\left({ }^{\mathrm{p}} \mathbf{B}-{ }^{\mathrm{p}} \mathbf{A}_{0}\right)-\left({ }^{\mathrm{b}} \mathbf{B}_{0}-{ }^{\mathrm{b}} \mathbf{A}\right) \cdot\left({ }^{\mathrm{b}} \mathbf{B}_{0}-{ }^{\mathrm{b}} \mathbf{A}\right)-\mathrm{b}^{2}$

$\mathrm{j}_{12}=-2\left({ }^{\mathrm{p}} \mathbf{B}-{ }^{\mathrm{p}} \mathbf{A}_{0}\right) \cdot{ }^{\mathrm{p}} \mathbf{m}$

$\mathrm{j}_{1}=-2\left({ }^{\mathrm{p}} \mathbf{C}-{ }^{\mathrm{p}} \mathbf{A}_{0}\right) \cdot{ }^{\mathrm{p}} \mathbf{m}$

$\mathrm{g}_{2}=\mathrm{q}^{2}+\mathrm{g}_{12} \mathrm{q}+\mathrm{g}_{02}$

$\mathrm{g}_{02}=\left({ }^{\mathrm{b}} \mathbf{C}_{0}-{ }^{\mathrm{b}} \mathbf{A}\right) \cdot\left({ }^{\mathrm{b}} \mathbf{C}_{0}-{ }^{\mathrm{b}} \mathbf{A}\right)-\left({ }^{\mathrm{p}} \mathbf{C}-{ }^{\mathrm{p}} \mathbf{A}_{0}\right) \cdot\left({ }^{\mathrm{p}} \mathbf{C}-{ }^{\mathrm{p}} \mathbf{A}_{0}\right)$

$\mathrm{g}_{12}=2\left({ }^{\mathrm{b}} \mathbf{C}_{0}-{ }^{\mathrm{b}} \mathbf{A}\right) \cdot{ }^{\mathrm{b}} \mathbf{s}$

Equations (3) form a system of three non-linear equations in three unknowns: $\varphi$, a and $q$.

An one-to-one correspondence exists between the triplets of $(\varphi, a, q)$ values that satisfy system (3) and the assembly modes of the SP-PS-RS structure.

In the next section, a univariate polynomial equation in $\mathrm{q}$ will be obtained by the successive elimination of $\varphi$ and a from Eqs. (3), then an analytic solution procedure for system (3) will be proposed.

\section{ANALYTIC Form SOLUTION OF THE Closure EQUATIONS}

Equation (3a) and (3b) are linear in $\cos \varphi$ and $\sin \varphi$ and give the explicit expressions

$\cos \varphi=\frac{g_{1} f_{2}-f_{1} j_{2}}{e_{1} f_{2}-f_{1} e_{2}}, \quad \sin \varphi=\frac{e_{1} j_{2}-g_{1} e_{2}}{e_{1} f_{2}-f_{1} e_{2}}$

that only depend on a and q.

The introduction of expressions (5) into the trigonometric 
identity $\cos ^{2} \varphi+\sin ^{2} \varphi=1$ yields

$\left(g_{1} f_{2}-f_{1} j_{2}\right)^{2}+\left(e_{1} j_{2}-g_{1} e_{2}\right)^{2}=\left(e_{1} f_{2}-f_{1} e_{2}\right)^{2}$

Equation (6) contains only the two unknowns a and q. The couples of (a, q) values that solve Eq. (6) are also solutions of Eqs. (3a) and (3b) where $\cos \varphi$ and $\sin \varphi$ are computed through expressions (5).

By expanding the expressions appearing in (6) and taking into account (4), Eq. (6) becomes

$\mathrm{p}_{4}\left(\mathrm{a}^{2}\right)^{2}+\mathrm{p}_{3}\left(\mathrm{a}^{2}\right) \mathrm{a}+\mathrm{p}_{2}\left(\mathrm{a}^{2}\right)+\mathrm{p}_{1} \mathrm{a}+\mathrm{p}_{0}=0$

where

$\mathrm{p}_{4}=\mathrm{f}_{1}^{2}+\mathrm{e}_{1}^{2} ; \mathrm{p}_{3}=2 \mathrm{j}_{12} \mathrm{p}_{4}$

$p_{2}=\left(j_{12}^{2}+2 j_{02}\right) p_{4}-2 g_{1}\left(e_{1} e_{2}+f_{1} f_{2}\right)$

$p_{1}=2 j_{12} j_{02} p_{4}-2 g_{1} j_{12}\left(e_{1} e_{2}+f_{1} f_{2}\right)$

$\mathrm{p}_{0}=\mathrm{j}_{02}{ }^{2} \mathrm{p}_{4}-2 \mathrm{~g}_{1} \mathrm{j}_{02}\left(\mathrm{e}_{1} \mathrm{e}_{2}+\mathrm{f}_{1} \mathrm{f}_{2}\right)+\mathrm{g}_{1}^{2}\left(\mathrm{f}_{2}^{2}+\mathrm{e}_{2}^{2}\right)$

$-\left(\mathrm{e}_{1} \mathrm{f}_{2}-\mathrm{f}_{1} \mathrm{e}_{2}\right)^{2}$.

Equations (7) and (3c) are two polynomial equations in a whose coefficients are univariate polynomials in q. Such equations constitute a system of two equations in the two unknowns a and $q$ whose solutions coincide with the solutions of system (3) where $\cos \varphi$ and $\sin \varphi$ are computed through expressions (5).

By substituting the right-hand side of Eq. (3c) for $\mathrm{a}^{2}$ into Eq. (7), expanding the resulting equation and, finally, substituting again the right-hand side of Eq. (3c) for $\mathrm{a}^{2}$ into the resulting equation, Eq. (7) becomes

$\mathrm{n}_{1} \mathrm{a}+\mathrm{n}_{0}=0$

where

$\mathrm{n}_{1}=-\left(\mathrm{g}_{2}+\mathrm{j}_{1}^{2}\right)\left(\mathrm{j}_{1} \mathrm{p}_{4}-\mathrm{p}_{3}\right)-\mathrm{j}_{1}\left(\mathrm{~g}_{2} \mathrm{p}_{4}+\mathrm{p}_{2}\right)+\mathrm{p}_{1}$,

$\mathrm{n}_{0}=\mathrm{g}_{2}\left[\mathrm{j}_{1}\left(\mathrm{j}_{1} \mathrm{p}_{4}-\mathrm{p}_{3}\right)+\mathrm{g}_{2} \mathrm{p}_{4}+\mathrm{p}_{2}\right]+\mathrm{p}_{0}$.

Equation (9) yields

$\mathrm{a}=-\frac{\mathrm{n}_{0}}{\mathrm{n}_{1}}$

that, when introduced into (3c), gives the following compatibility equation

$\mathrm{n}_{0}^{2}-\mathrm{j}_{1} \mathrm{n}_{0} \mathrm{n}_{1}-\mathrm{g}_{2} \mathrm{n}_{1}^{2}=0$

Equation (12) is a univariate twelfth-degree polynomial equation [see (4), (8) and (10)] whose only unknown is q. The analysis of (12) shows that the values of $q$ which make $n_{1}$ equal to zero are solution of (12) only if they also make $n_{0}$ equal to zero, and, in addition, the values of $\mathrm{q}$, that make $\mathrm{n}_{0}$ and $n_{1}$ contemporarily equal to zero, are roots of Eq. (12) with even multiplicity.

By using expressions (10) (see the Appendix), it can be demonstrated that, when $\mathrm{n}_{0}$ and $\mathrm{n}_{1}$ are contemporarily equal to zero, the fourth-degree polynomial equation (7) can be factorized as the product of Eq. (3c) by a univariate quadratic polynomial in a [i.e. Eq. (3c) is contained in Eq. (7)]. Therefore, two values of a are associated to each value of $q$, that makes $\mathrm{n}_{0}$ and $\mathrm{n}_{1}$ contemporarily equal to zero, in the solution of the system constituted by Eqs. (3c) and (7). These two values of a are the two solutions of the quadratic Eq. (3c) where the value of $\mathrm{q}$, that makes $\mathrm{n}_{0}$ and $\mathrm{n}_{1}$ contemporarily equal to zero, has been introduced in the expression of $g_{2}$ [see (4p)].

Finally, it is worth noting that, if $\left(\mathrm{e}_{1} \mathrm{f}_{2}-\mathrm{f}_{1} \mathrm{e}_{2}\right)$ is equal to zero for a given couple of (q, a) values that solve Eqs. (3c) and (7), the two Eqs. (3a) and (3b) are not independent and expressions (5) cannot be used to compute $\varphi$. In this case, two values of $\varphi$ that contemporarily solve Eqs. (3a) and (3b) exist. Both these solutions can be computed by solving the quadratic equation in $\tan (\varphi / 2)$ that is obtained from either Eq. (3a) or Eq. (3b) after the introduction of the following trigonometric identities:

$\sin \varphi=\frac{2 \tan (\varphi / 2)}{1+\tan ^{2}(\varphi / 2)}, \quad \cos \varphi=\frac{1-\tan ^{2}(\varphi / 2)}{1+\tan ^{2}(\varphi / 2)}$.

The obtained results suggest the implementation of the following algorithm for solving the closure equations of a SPPS-RS structure:

(i) all the values of q that solve Eq. (12) are computed by using a standard software package that computes all the roots of a polynomial equation in the complex field;

(ii) for each real value of $\mathrm{q}$, computed in the previous step, the values of $\mathrm{n}_{0}$ and $\mathrm{n}_{1}$ are computed by using relationships (10); if $\mathrm{n}_{0}$ and $\mathrm{n}_{1}$ are not contemporarily equal to zero, the corresponding value of a is computed through relationship (11), otherwise the corresponding two values of a are computed by solving Eq. (3c);

(iii) for each couple of (q, a) values, determined in the previous step, if the corresponding value of $\left(e_{1} f_{2}-f_{1} e_{2}\right)$ is different from zero, one value of $\varphi$ is calculated by using relationships (5), otherwise two values of $\varphi$ are computed by solving one out of Eqs. (3a) and (3b) after the introduction of the trigonometric identities (13).

Since the real solutions of Eq. (12) are at most twelve, the assembly modes of any SP-PS-RS structure are at most twelve and the solutions of the forward position analysis of any parallel manipulator, which generates a SP-PS-RS structure when the active joints are locked, are as many. 


\section{NUMERICAL EXAMPLE}

With reference to the introduced notations (see Fig. 5), the proposed procedure has been applied to an SP-PS-RS structure defined by the following data (the lengths are measured in an arbitrary length unit): ${ }^{\mathrm{b}} \mathbf{B}_{0}=\{2,0,0\}^{\mathrm{T}},{ }^{\mathrm{b}} \mathbf{C}_{0}=\{1,1,4\}^{\mathrm{T}},{ }^{\mathrm{b}} \mathbf{A}=$ $\{0,0,0\}^{\mathrm{T}},{ }^{\mathrm{b}} \mathbf{s}=\{-1,0,0\}^{\mathrm{T}},{ }^{\mathrm{b}} \mathbf{u}=\{0,1,0\}^{\mathrm{T}},{ }^{\mathrm{b}} \mathbf{v}=\{-1,0,0\}^{\mathrm{T}}$, ${ }^{\mathrm{p}} \mathbf{A}_{0}=\{0,0,0\}^{\mathrm{T}},{ }^{\mathrm{p}} \mathbf{C}=\{-1,1,4\}^{\mathrm{T}},{ }^{\mathrm{p}} \mathbf{B}=\{2,0,4\}^{\mathrm{T}},{ }^{\mathrm{p}} \mathbf{m}=\{0$, $-1,0\}^{\mathrm{T}}$ and $\mathrm{b}=4$.

By using the above-reported procedure the four real assembly modes listed in Table I and the eight complex assembly modes listed in Table II have been determined.

In Tables I and II, each row corresponds to one assembly mode (real or complex); columns 2, 3 and 4 report the values of the joint variables q, a and $\varphi$; whereas, columns 5, 6 and 7 report the components of the position vectors ${ }^{\mathrm{b}} \mathbf{B},{ }^{\mathrm{b}} \mathbf{C}$ and ${ }^{\mathrm{p}} \mathbf{A}$ that, together with the data, allow closure equations (1) to be easily checked.

All the twelve solutions verify system (1) which proves that the elimination process used to deduce Eq. (12) does not introduce extraneous roots.

\section{CONCLUSION}

The analytic solution of the forward position analysis of all the three-legged parallel manipulators that become structures with topology SP-PS-RS when their active joints are locked has been presented.

In particular, since the assembly modes of an SP-PS-RS structure one-to-one correspond to the FPA solutions of the PMs that become that structure when their active joints are locked, the closure equation system of a generic SP-PS-RS structure has been written in the form of three non-linear equations in three unknowns. The solution of such a non-linear system has been reduced to the determination of the roots of a univariate twelfth-degree polynomial equation plus one simple back substitution procedure. The proposed algorithm of solution has been applied to a real case.

The result of this study is that the solutions of the FPA of all the PMs which becomes SP-PS-RS structures, when their active joints are locked, are at most twelve and can be found through the proposed algorithm.

This work closes a research activity devoted to develop efficient algorithms for the analytical solution of the FPA of three-legged PMs which, when their active joints are locked, become closed structures with three connectivity-four legs constituted by a spherical pair in series with either a prismatic pair or a revolute pair (i.e. legs of the following types: PS, RS, $\mathrm{SP}$ and SR). There are ten different types of such structures: 3PS, 3RS, PS-2RS, RS-2PS, SP-2PS, SR-2RS, SR-2PS, SP2RS, SR-PS-RS and SP-PS-RS. The results of this activity are summarized in Table III.

TABLE I: RESULTS OF THE NUMERICAL EXAMPLE: REAL ASSEMBLY MODES OF THE SP-PS-RS STRUCTURE (THE LENGTHS ARE MEASURED IN AN ARBITRARY LENGTH UNIT, WHEREAS $\varphi$ IS MEASURED IN DEGREES).

\begin{tabular}{|c|c|c|c|c|c|c|}
\hline (THE LENGTHS ARE MEASURED IN AN ARBITRARY LENGTH UNIT, WHEREAS $\varphi$ IS MEASURED IN DEGREES). \\
\hline No. & $\mathrm{q}$ & $\mathrm{a}$ & $\varphi$ & ${ }^{\mathrm{b}} \mathbf{B}$ & ${ }^{\mathrm{b}} \mathbf{C}$ & ${ }^{\mathrm{p}}$ A \\
\hline 1 & -3.91561 & 3.91561 & 163.39 & $\{5.83300,0,1.14371\}^{\mathrm{T}}$ & $\{4.91561,1,4\}^{\mathrm{T}}$ & $\{0,-3.91561,0\}^{\mathrm{T}}$ \\
\hline 2 & -1.53884 & -3.53884 & 141.51 & $\{5.13085,0,2.48954\}^{\mathrm{T}}$ & $\{2.53884,1,4\}^{\mathrm{T}}$ & $\{0,3.53884,0\}^{\mathrm{T}}$ \\
\hline 3 & 1.46398 & -1.46398 & 97.698 & $\{2.53581,0,3.96395\}^{\mathrm{T}}$ & $\{-0.46398,1,4\}^{\mathrm{T}}$ & $\{0,1.46398,0\}^{\mathrm{T}}$ \\
\hline 4 & 2 & 0 & 90 & $\{2,0,4\}^{\mathrm{T}}$ & $\{-1,1,4\}^{\mathrm{T}}$ & $\{0,0,0\}^{\mathrm{T}}$ \\
\hline
\end{tabular}

TABLE II: RESULTS OF THE NUMERICAL EXAMPLE: COMPLEX ASSEMBLY MODES OF THE SP-PS-RS STRUCTURE $(\mathrm{j}=\sqrt{-1}$, THE LENGTHS ARE MEASURED IN AN ARBITRARY LENGTH UNIT, WHEREAS $\varphi$ IS MEASURED IN DEGREES).

\begin{tabular}{|c|c|c|c|c|c|c|}
\hline No. & $\mathrm{q}$ & $\mathrm{a}$ & $\varphi$ & ${ }^{\mathrm{b}}$ & ${ }^{\mathrm{b}} \mathbf{C}$ & ${ }^{\mathrm{P}} \mathbf{A}$ \\
\hline 1 & $-1.32422-\mathrm{j} 4.08343$ & $-3.32422-\mathrm{j} 4.08343$ & $79.84+\mathrm{j} 75.22$ & $\{0.594018+\mathrm{j} 6.78711$, & $\{2.32422+\mathrm{j} 4.08343$, & $\{0,3.32422+\mathrm{j} 4.08343$, \\
& & & $0,7.84647+\mathrm{j} 1.21616\}^{\mathrm{T}}$ & $1,4\}^{\mathrm{T}}$ & $0\}^{\mathrm{T}}$ \\
\hline 2 & $-1.32422+\mathrm{j} 4.08343$ & $-3.32422+\mathrm{j} 4.08343$ & $79.84-\mathrm{j} 75.22$ & $\{0.594018-\mathrm{j} 6.78711$, & $\{2.32422-\mathrm{j} 4.08343$, \\
& & & $0,7.84647-\mathrm{j} 1.21616\}^{\mathrm{T}}$ & $1,4\}^{\mathrm{T}}$ & $\{0,3.32422-\mathrm{j} 4.08343$, \\
$0\}^{\mathrm{T}}$ & \\
\hline 3 & $2.09364-\mathrm{j} 3.95557$ & $.0936413-\mathrm{j} 3.95557$ & $-15.60+\mathrm{j} 9.819$ & $\{-1.90944-\mathrm{j} 0.185202$, & $\{-1.09364+\mathrm{j}$ & $\{0,-0.0936413+\mathrm{j}$ \\
& & & & $0,-1.09124+\mathrm{j} 0.663502\}^{\mathrm{T}}$ & $3.95557,1,4\}^{\mathrm{T}}$ & $3.95557,0\}^{\mathrm{T}}$ \\
\hline 4 & $2.09364+\mathrm{j} 3.95557$ & $.0936413+\mathrm{j} 3.95557$ & $-15.60-\mathrm{j} 9.819$ & $\{-1.90944+\mathrm{j} 0.185202,0$, & $\{-1.09364-\mathrm{j}$ & $\{0,-0.0936413-\mathrm{j}$ \\
& & & & $-1.09124-\mathrm{j} 0.663502\}^{\mathrm{T}}$ & $3.95557,1,4\}^{\mathrm{T}}$ & $3.95557,0\}^{\mathrm{T}}$ \\
\hline 5 & $-2.34499-\mathrm{j} 3.3943$ & $2.34499+\mathrm{j} 3.39430$ & $74.81+\mathrm{j} 51.74$ & $\{0.49444+\mathrm{j} 3.979800$, & $\{3.34499+\mathrm{j} 3.39430$, & $\{0,-2.34499-\mathrm{j}$ \\
& & & $0,5.54437+\mathrm{j} 1.08071\}^{\mathrm{T}}$ & $1,4\}^{\mathrm{T}}$ & $3.39430,0\}^{\mathrm{T}}$ \\
\hline 6 & $-2.34499+\mathrm{j} 3.3943$ & $2.34499-\mathrm{j} 3.39430$ & $74.81-\mathrm{j} 51.74$ & $\{0.49444-\mathrm{j} 3.979800$, & $\{3.34499-\mathrm{j} 3.39430$, & $\{0,-2.34499+\mathrm{j}$ \\
& & & & $0,5.54437-\mathrm{j} 1.08071\}^{\mathrm{T}}$ & $1,4\}^{\mathrm{T}}$ & $3.39430,0\}^{\mathrm{T}}$ \\
\hline 7 & $0.57081-\mathrm{j} 4.24749$ & $-0.57081+\mathrm{j} 4.24749$ & $-25.35+\mathrm{j} 37.76$ & $\{-2.42884-\mathrm{j} 1.21226,0$, & $\{0.429190+\mathrm{j} 4.24749$, & $\{0,0.570810-\mathrm{j} 4.24749$, \\
& & & & $-2.09820+\mathrm{j} 2.55881\}^{\mathrm{T}}$ & $1,4\}^{\mathrm{T}}$ & $0\}^{\mathrm{T}}$ \\
\hline 8 & $0.57081+\mathrm{j} 4.24749$ & $-0.57081-\mathrm{j} 4.24749$ & $-25.35-\mathrm{j} 37.76$ & $\{-2.42884+\mathrm{j} 1.21226,0$, & $\{0.429190-\mathrm{j} 4.24749$, & $\{0,0.570810+\mathrm{j} 4.24749$, \\
& & & $-2.09820-\mathrm{j} 2.55881\}^{\mathrm{T}}$ & $1,4\}^{\mathrm{T}}$ & $0\}^{\mathrm{T}}$ \\
\hline
\end{tabular}


TABLE III: SUMMARY OF THE RESULTS

\begin{tabular}{|c|c|c|}
\hline Structure & Assembly modes & Reference \\
\hline 3PS & 8 & {$[33]$} \\
\hline 3RS & 16 & {$[31]$} \\
\hline PS-2RS & 16 & {$[34]$} \\
\hline RS-2PS & 12 & {$[34]$} \\
\hline SP-2PS & 8 & {$[35]$} \\
\hline SR-2RS & 16 & {$[32]$} \\
\hline SR-2PS & 8 & {$[36]$} \\
\hline SP-2RS & 16 & {$[37]$} \\
\hline SR-PS-RS & 12 & {$[38]$} \\
\hline SP-PS-RS & 12 & {$[$ This paper] } \\
\hline
\end{tabular}

\section{APPENDIX}

If $\mathrm{n}_{0}$ and $\mathrm{n}_{1}$ contemporarily vanish, then expressions (10) yield:

$p_{1}=\left(g_{2}+j_{1}^{2}\right)\left(j_{1} p_{4}-p_{3}\right)+j_{1}\left(g_{2} p_{4}+p_{2}\right)$,

$p_{0}=-g_{2}\left[j_{1}\left(j_{1} p_{4}-p_{3}\right)+g_{2} p_{4}+p_{2}\right]$.

The substitution of expressions (A.1) and (A.2) for $\mathrm{p}_{1}$ and $\mathrm{p}_{0}$, respectively, into Eq. (7) yields

$$
\begin{aligned}
& p_{4}\left(a^{2}\right)^{2}+p_{3}\left(a^{2}\right) a+p_{2}\left(a^{2}\right)+a\left[\left(g_{2}+j_{1}{ }^{2}\right)\left(j_{1} p_{4}-p_{3}\right)\right. \\
& \left.+j_{1}\left(g_{2} p_{4}+p_{2}\right)\right]-g_{2}\left[j_{1}\left(j_{1} p_{4}-p_{3}\right)+g_{2} p_{4}+p_{2}\right]=0
\end{aligned}
$$

Equation (A.3) can be factorized as follows [note that, by expanding (A.3) and (A.4), the resulting equations coincide]:

$\left[p_{4} a^{2}+\left(p_{3}-j_{1} p_{4}\right) a+g_{2} p_{4}+p_{2}+j_{1}\left(j_{1} p_{4}-p_{3}\right)\right]\left(a^{2}\right.$

$\left.+\mathrm{j}_{1} \mathrm{a}-\mathrm{g}_{2}\right)=0$

If the second factor of the expression at the left-hand side of Eq. (A.4) is equated to zero, an equation that coincide with Eq. (3c) is obtained, which proves that, if $n_{0}$ and $n_{1}$ contemporarily vanish, Eq. (3c) is contained in Eq. (7).

\section{REFERENCES}

[1] Gough, V.E., 1956, "Contribution to discussion to papers on research in automobile stability and control and in tyre performance," by Cornell Staff, Proc. Auto. Div. Instn. Mech. Engrs., 1956, pp. 392-395.

[2] Stewart, D., 1965, "A platform with six degrees of freedom," Proc. Instn. Mech. Engrs., (1965), Vol. 180 (Part 1), No. 15, pp. 371-376.

[3] Higuchi, T., Ming, A. and Jiang-Yu, J., 1988, "Application of multidimensional wire crane in construction," Proc. of the $5^{\text {th }}$ Int. Symp. on Robotics in Construction, ISARC'88, Tokyo, June 6-8, 1988, pp. 661668.

[4] Arai, T., Cleary, K., Homma, K., Adachi, H. and Nakamura, T., 1991, "Development of parallel link manipulator for underground excavation task," Proc. of the 1991 Int. Sym. on Advanced Robot Technology, pp. 541-548.

[5] Albus, J., Bostelman, R. and Dagalakis, N., 1993, "The NIST ROBOCRANE," Journal of Robotic Systems, Vol. 10, No. 5 (July, 1993), pp. 709- 724.

[6] Viscomi, B.V., Michalerya, W.D. and Lu, L.-W, 1994, "Automated construction in the ATLSS integrated building systems," Automation in Construction, Vol. 3, No. 1 (May, 1994), pp.35-43.

[7] Bostelman, R., Albus, J., Dagalakis, N. and Jacoff, A., 1996, "BOBOCRANE project: an advanced concept for large scale manufacturing," Proc. of the 1996 Int. Conf. of the Association for Unmanned Vehicle Systems, Orlando, July 15-19, 1996, pp. 509-521.

[8] Gosselin, C.M. and Angeles, J., 1988, "The optimum kinematic design of a planar three-degree-of-freedom parallel manipulator," $A S M E$ Journal of Mechanisms, Transmission and Automation in Design, Vol. 110 (1988), No. 2, pp. 35-41.

[9] Clavel, R., 1988, "DELTA: a fast robot with parallel geometry," Proc. of the 18th International Symposium on Industrial Robots, Sydney, Australia, 1988, pp. 91-100.

[10] Tsai, L.W., 1996, "Kinematics of a three-dof platform with three extensible limbs," Recent Advances in Robot Kinematics, J. Lenarcic and V. Parenti-Castelli (Editors), Kluwer Academic Publishers, 1996, pp. 401-410.

[11] Stamper, R.E., Tsai, L.W. and Walsh, G.C., 1997, "Optimization of a three dof translational platform for well-conditioned workspace," Proc. of IEEE International Conference on Robotics and Automation, 1997, paper No. A1-MF-0025.

[12] Di Gregorio, R. and Parenti-Castelli, V., 1998, "A translational 3-dof parallel manipulator," Advances in Robot Kinematics: Analysis and Control, J. Lenarcic and M.L. Husty (Editors), Kluwer Academic Publishers, 1998, pp. 49-58;

[13] Di Gregorio, R., 2000, "Closed-Form solution of the position analysis of the pure translational 3-RUU parallel mechanism," Proc. of the 8th Symposium on Mechanisms and Mechanical Transmissions, MTM 2000, Timisoara, Romania, 2000.

[14] Kong, X. and Gosselin, C.M., 2004, "Type synthesis of 3-DOF translational parallel manipulators based on screw theory," $A S M E$ Journal of Mechanical Design, Vol. 126, No.1 (January, 2004), pp.8392.

[15] Gosselin, C.M. and Angeles, J., 1989, "The optimum kinematic design of a spherical three-degree-of-freedom parallel manipulator," $A S M E$ Journal of Mechanisms, Transmission and Automation in Design, Vol. 111 (1989), No. 2, pp. 202-207.

[16] Agrawal, S.K., Desmier, G. and Li, S., 1995, "Fabrication and analysis of a novel 3-dof parallel wrist mechanism," ASME Journal of Mechanical Design, Vol. 117 (1995), No. 2A, pp. 343-345.

[17] Karouia, M. and Hervé, J.M., 2000, "A three-dof tripod for generating spherical rotation," Advances in Robot Kinematics, J. Lenarcic and M.M. Stanisic (Editors.), Kluwer Academic Publishers, Netherlands, 2000, pp. 395-402.

[18] Di Gregorio, R., 2001, "Kinematics of a new spherical parallel manipulator with three equal legs: the 3-URC wrist," Journal of Robotic Systems, Vol. 18 (2001), No. 5, pp. 213-219.

[19] Karouia, M. and Hervé, J.M., 2002, "A family of novel orientational 3DOF parallel robots," Proc. RoManSy'14, Udine, July 1-4, 2002, pp. 359-368.

[20] Kong, X. and Gosselin, C.M., 2004, "Type synthesis of 3-DOF spherical parallel manipulators based on screw theory," ASME Journal of Mechanical Design, Vol. 126, No.1 (January, 2004), pp.101-108.

[21] Karouia, M. and Hervé, J.M., 2004, "New parallel wrists: special limbs with motion dependency," On Advances in Robot Kinematics, J. Lenarcic and C. Galletti (Editors), Kluwer Academic Publishers, 2004, pp.371-380.

[22] Ceccarelli, M., 1997, "A new three d.o.f. spatial parallel mechanism," Mechanism and Machine Theory, Vol. 32 (1997), No. 8, pp. 896-902

[23] Di Gregorio, R. and Parenti-Castelli, V., 2001, "Position analysis in analytical form of the 3-PSP mechanism," ASME Journal of Mechanical Design, Vol. 123, No. 2 (March, 2001), pp.51-55.

[24] Hervé, J.M., 2004, "Parallel mechanisms with pseudo-planar motion generators," On Advances in Robot Kinematics, J. Lenarcic and C. Galletti (Editors), Kluwer Academic Publishers, 2004,, pp.431-440.

[25] Tsai, L.-W., 1999, "Robot analysis: the mechanics of serial and parallel manipulators," John Wiley \& Sons, Inc., New York, p. 14.

[26] Innocenti, C. and Parenti-Castelli, V., 1994, "Exhaustive enumeration of fully-parallel kinematic chains," Proc. of ASME 1994 Int. Annual Winter Meeting, Chicago (IL), USA, DSC-Vol. 55-2, Dynamic System and Control, pp. 1135-1141.

[27] Wampler, C. W., 1996, "Forward displacement analysis of general sixin-parallel SPS (Stewart) platform manipulators using Soma coordinates," Mechanism and Machine Theory, Vol. 31, No. 3, pp. 331337. 
[28] Husty, M. L., 1996, "An algorithm for solving the direct kinematics of general Stewart - Gough platforms," Mechanism and Machine Theory, Vol. 31, No. 4, pp. 365-380.

[29] Innocenti, C., 2001, "Forward kinematics in polynomial form of the general Stewart platform," ASME Journal of Mechanical Design, Vol. 123, No. 2, pp. 254-260.

[30] Lee, T.-Y. and Shim, J.-K., 2001, "Forward kinematics of the general 66 Stewart platform using algebraic elimination," Mechanism and Machine Theory, Vol. 36, No. 10, pp. 1073-1085.

[31] Innocenti, C. and Parenti-Castelli, V., 1990, "Direct position analysis of the Stewart platform mechanism," Mechanism and Machine Theory, Vol. 25, No. 6, pp. 611-621.

[32] Innocenti, C. and Parenti-Castelli, V., 1991, "Direct kinematics of the reverse Stewart platform mechanism," Proc. of the 1991 IFAC Simposium on Robot Control, Siroco'91, Vienna, Austria, pp. 75-80.

[33] Parenti-Castelli, V. and Innocenti, C., 1990, "Direct displacement analysis for some classes of spatial parallel mechanisms," Proc. of the $8^{\text {th }}$ CISM-IFToMM Symp. on Theory and Practice of Robots and Manipulators, Cracow, Poland (1990), pp. 126-133.

[34] Parenti-Castelli, V. and Innocenti, C., 1992, "Forward displacement analysis of parallel mechanisms: closed form solution of PRR-3S and
PPR-3S structures," ASME Journal of Mechanical Design, Vol. 114, No. 1, pp. 68-73.

[35] Di Gregorio, R., 2004, "Direct position analysis of parallel manipulators which generate SP-2PS structures," ROBOTICA, in press.

[36] Di Gregorio, R., 2004, "Direct position analysis in analytical form of parallel manipulators generating structures with topology SR-2PS," Proc. of ASME 2004 Design Engineering Technical Conferences and Information in Engineering Conference, DETC'04, September 28 October 2, 2004, Salt Lake City, Utah USA, Paper No. DETC200457036

[37] Di Gregorio, R., 2004, "Analytic form solution of the direct position analysis of the SP-2RS architectures," Proc. of ASME 2004 Design Engineering Technical Conferences and Information in Engineering Conference, DETC'04, September 28 - October 2, 2004, Salt Lake City, Utah USA, Paper No. DETC2004-57037

[38] Di Gregorio, R., 2005, "Analytic form solution of the forward position analysis of three-legged parallel mechanisms generating SR-PS-RS structures," Proc. of the $22^{\text {nd }}$ Int. Symp. on Robotics and Automation in Construction, ISARC'05, Ferrara (Italy), September 11-14, 2005. 